\title{
Particle Swarm Optimization Based Approach for Estimation of Costs and Duration of Construction Projects
}

\author{
Tarq Zaed Khalaf a , Hakan Çağlar ${ }^{\text {a }}$, Arzu Çağlar ${ }^{\mathrm{b}}$, Ammar N. Hanoon ${ }^{\mathrm{c} *}$ \\ ${ }^{a}$ Department of Engineering Management, Faculty of Engineering and Architecture, Kastamonu University, Turkey. \\ ${ }^{b}$ Sebahat-Mesut Yilmaz, Vocational School, Kastamonu University, Turkey. \\ ${ }^{c}$ Department of Reconstruction and Projects, University of Baghdad, Baghdad, Iraq.
}

Received 26 October 2019; Accepted 12 January 2020

\begin{abstract}
Cost and duration estimation is essential for the success of construction projects. The importance of decision making in cost and duration estimation for building design processes points to a need for an estimation tool for both designers and project managers. Particle swarm optimization (PSO), as the tools of soft computing techniques, offer significant potential in this field. This study presents the proposal of an approach to the estimation of construction costs and duration of construction projects, which is based on PSO approach. The general applicability of PSO in the formulated problem with cost and duration estimation is examined. A series of 60 projects collected from constructed government projects were utilized to build the proposed models. Eight input parameters, such as volume of bricks, the volume of concrete, footing type, elevators number, total floors area, area of the ground floor, floors number, and security status are used in building the proposed model. The results displayed that the PSO models can be an alternative approach to evaluate the cost and-or duration of construction projects. The developed model provides high prediction accuracy, with a low mean $(0.97$ and $0.99)$ and $\mathrm{CoV}(10.87 \%$ and $4.94 \%)$ values. A comparison of the models' results indicated that predicting with PSO was importantly more precise.
\end{abstract}

Keywords: Cost; Duration; Construction Project; Particle Swarm Optimization; Managing Projects; Decision Making.

\section{Introduction}

The cost and duration prediction is considered an essential issue in construction projects. Underestimation and overestimation of costs may result from the failure of a construction project. The utilize of various approaches in the entire project lifetime should supply information on costs to the contributors to the project and support a complicated decision-making process [1,2]. Cost and duration evaluating is a vital task for costing and tender preparation for any construction project before they are built. Cost and duration estimation in the early steps of construction projects comprises a considerable doubt. Hence, there is a high request to construct an active approach to minimize uncertainty in cost and duration prediction. One traditional technique for predicting the cost and duration values is the utilize of several specialists. Nevertheless, continuous contact with these specialists is not always an easy choice, producing to improve the alternative method to predict the cost and duration of construction projects. It is preferred to construct the new method according to datasets created from the preceding similar projects. Furthermore, utilizing the traditional technique is difficult and complicated. Hence, utilizing a soft-computing method is a noticeably, more effective way to address nonlinear problems. The best solutions for any system can be defined as the viable solutions with fitness values,

* Corresponding author: anh@uobaghdad.edu.iq

http://dx.doi.org/10.28991/cej-2020-03091478

(C) 2019 by the authors. Licensee C.E.J, Tehran, Iran. This article is an open access article distributed under the terms and conditions of the Creative Commons Attribution (CC-BY) license (http://creativecommons.org/licenses/by/4.0/). 
as well as the values of any other sustainable solutions; these solutions are achieved by selecting values for the set of parameters that satisfy all constraint solutions [3]. Furthermore, optimization approaches are utilized widely in numerous areas, such as engineering and computer science. Study in the optimization area is very active, and new optimization approaches are being developed frequently [4]. The main goal of optimization methods is to find values for a set of parameters that maximize or minimize objective functions that are subject to certain constraints [5]. Through the last decades, numerous researches have been achieved to develop optimization approaches that apply evolutionary programming methods.

A relationship between completed construction cost and the time taken to complete a construction project was first mathematically established by Bromilow (1974) [6]. A regression analysis was utilized by Carr (1979) [7] to organize the duration and cost preparation of industrial buildings. Based on the neural network technique, Wang et al. (2013) [8] proposed a cost estimator model. The learning steps of their neural network were accomplished using a particle swarm optimization (PSO) method. In 2014, a hybrid model PSO-BPNN was proposed by Hong et al. (2014) [9] to assess the cost of construction projects. The PSO technique in the network has optimized the ANN weights. In 2015, Zima (2015) [10] presented a CBR model to predict the construction elements unit price. The CBR method shows a knowledge base that supports the cost prediction at the initial step of a construction project. A hybrid model ANN-ACO and ANN model for determining the amount and cost of construction waste in the early stage of construction were developed by Lee et al. (2016) [11] using "ant colony optimization" ACO algorithm to optimize the ANN weights and ANN model In 2018, a proposed model for predicting the construction costs of sports areas was presented by Juszczyk et al. (2018) [12]. Hybrid DES-PSO model that includes discrete event simulation (DES) and particle swarm optimization (PSO) algorithms were developed by Hegazy et al. (1994) [13] construction through a set of iterations in networks utilized, that significantly reduces efforts in search optimization scenarios.

The main target of the current research is to propose and investigate models of cost and duration estimating for the construction projects in the initial planning stage using particle swarm optimization (PSO) technique. The proposed PSO models can assist the engineers in making informed decisions in the initial stages of the design steps. With these models, it is probable to acquire a precise estimation, even when suitable information is not obtainable in the initial phases. These approaches encourage a feedback procedure that may support designers to attain the best solution. Moreover, the proposed models considered some category parameters, such as the security status that has been happened in Iraq in the last decade.

\section{Research Methodology}

Soft-computing methods are utilized to overcome complicated numerical optimization problems as non-linear systems. The current study tries to propose PSO models for predicting the cost and duration of construction projects accurately. The primary purpose of this study is to adopt and propose new models for the duration/cost assessment of construction projects utilizing the PSO algorithm. The proposed models were developed according to numerous, affecting input parameters, as presented below. The definition of the input parameters is listed in Table 1.

Cost $/$ Duration $=f(C, B, E N, F T, A G F, T F A, F N, S S)$

Table 1. Definition of the input parameters

\begin{tabular}{cl}
\hline Parameter & Definition \\
\hline$C$ & The concrete volume: The concrete works comprise lean concrete, screed concrete, foundation, columns, beams, and slabs. \\
$B$ & The brick volume. \\
$F T$ & The number of elevators in the buildings. \\
$A G F$ & Types of footing: 1- Raft footing and 2-Separated footing. \\
$T F A$ & The total area of floors. \\
$F N$ & The floors number. \\
$S S$ & The security status: 1- Safe, 2-Moderate and 3- Not safe \\
\hline
\end{tabular}

Optimization is required to produce optimal cost and-or duration values for a construction project. Of three key points must be taken in its progress:

(a) The objective function must be formulated.

(b) A clear approach is required to solve the optimization problem.

(c) The convergence criterion should be specified.

These detailed items will be discussed in the subsequent sections. 


\subsection{Objective Function of PSO Models}

The primary objective of PSO is to optimize the cost and-or duration values and exploration for an optimum set of unknown coefficients, as illustrated in the proposed model section from within the solution space. The actual and forecast values of the duration and cost amount were detected to have minimal differences when using the final form of the optimized model. The proposed models are simulated utilizing MATLAB to optimize the duration and cost amount model for the construction projects. The objective function used in this study is the root mean square error (RMSE). This objective function can be accounted for utilizing the following expression [14-17]:

$$
R M S E=\frac{1}{n} \sum_{i=1}^{n}\left|y-y^{\prime}\right|
$$

Where $y^{\prime}$ refers to the forecasted value, $y$ refers to the actual value, and $n$ denotes to the number of dataset samples.

\subsection{Optimization Method of PSO Models}

As a result of its global convergence ability, easy implementation, and adoption, PSO is considered one of the best optimization approaches. PSO is an evolutionary computation approach developed by Eberhart et al. (2001) [18], which was inspired by the social behavior of bird (particle) flocking. The PSO algorithm is generally accepted and used in solving different optimization problems. During the entire search process, the position and velocity of each particle can be updated according to Equations 3 and 4.

$$
\begin{aligned}
& V_{i}(t+1)=w V_{i}(t)+c_{1} \operatorname{Rand}_{(\cdot)_{1}} \mid \text { pbest }_{i} t-X_{i}(t)\left|+c_{2} \operatorname{Rand}_{(\cdot)_{2}}\right| \text { gbest }_{i} t-X_{i}(t) \mid \\
& X_{i}(t+1)=X_{i}(t)+V_{i}(t+1)
\end{aligned}
$$

Where $V_{i}$ and $X_{i}$ are the velocity and position of the particles, respectively; $\operatorname{Rand}(\cdot)_{1}$ and $\operatorname{Rand}(\cdot)_{2}$ are $\operatorname{random}$ numbers that are uniformly distributed between 0 and 1 ; pbest denotes the best position of each particle in space, and gbest represents the globally best position of all the particles. Acceleration coefficients $c_{1}$ and $c_{2}$ describe the 'trust' settings that mention the degree of confidence in the optimal solution found by an individual particle ( $c_{1}$-cognitive parameter) and by the whole swarm $\left(c_{2}\right.$-social parameter). The term $w$ in Equation 3 refers to the inertial weight that was presented to improve the convergence of the iteration procedure. This weight is a scaling factor utilized to control the search capabilities of the swarm, which scales the current velocity value that affects the updated velocity vector. Later, Shi and Eberhart (1998) [19] developed the original PSO algorithm by adding the inertial weight; thus, this weight was not a portion of the original one.

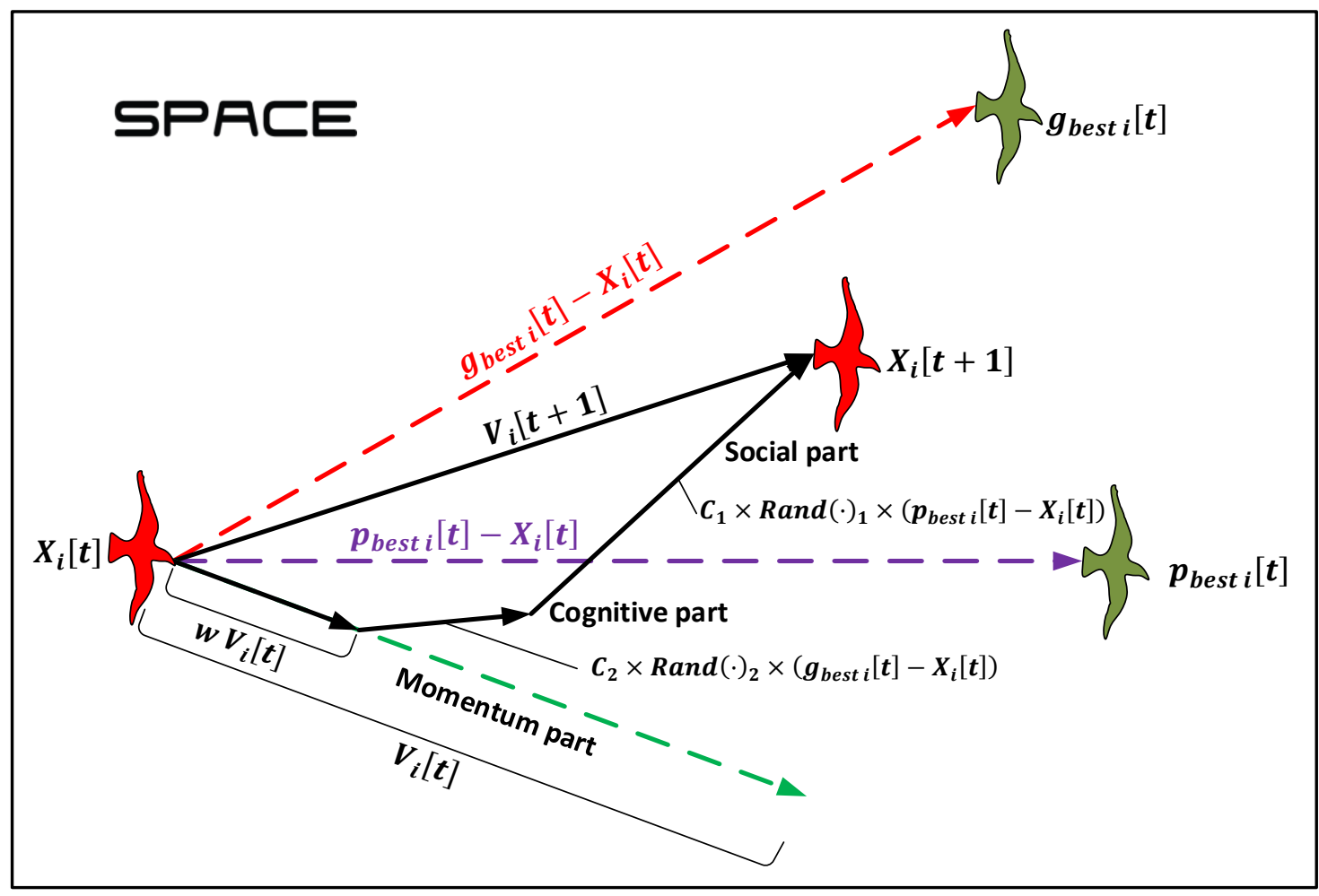

Figure 1. Pictorial view of particle behavior showing position and velocity update [20] 
Figure 1 displays the updated particle position and velocity of the $2 \mathrm{D}$ parameter space. The first vector refers to the momentum velocity of the particles in the previous stage. The second vector refers to the particle memory components that get the best position as a result of iteration. This speed component attracted the particle to the best position in the solution space. So, the last vector is called a social component or swarm. The particle in this component is attracted to the best position in the swarm [20].

\subsection{Convergence Criteria}

Convergence criteria must be applied to end the process of optimization during the repeated search [21, 22]. The maximum number of iterations and minimum error requirements are the convergence criteria adopted in the PSO algorithm. The complexity of the optimization problem determines the maximum number of iterations. Previous knowledge of the optimal global error value determines the minimum error of the algorithm, which is possible to test or adjust the algorithm in mathematical problems when optimization is known a priori. Table 2 lists the main PSO parameters. Table 3 illustrate the convergence parameters of the PSO utilized in the current study [23].

Table 2. Main PSO parameters [23]

\begin{tabular}{ll}
\hline \multicolumn{1}{c}{ Description } & \multicolumn{1}{c}{ Details } \\
\hline Number of particles, $N P$ & $\begin{array}{l}\text { A typical range is } 10-40 \text {. For some difficult or special problems, the } \\
\text { number can be increased to } 50-100\end{array}$ \\
The dimension of particles, $n$ & $\begin{array}{l}\text { It is determined by the problem to be optimized. } \\
\text { Usually is set to a value less than } 1 \text {, and for faster convergence, } w=0.7\end{array}$ \\
Inertia weight, $w$ & $\begin{array}{l}\text { is considered. } \\
\text { They are determined by the problem to be optimized. Different ranges } \\
\text { Vectors containing the lower and upper bounds of the } n\end{array}$ \\
design variables, respectively, $\boldsymbol{x}^{L}, \boldsymbol{x}^{U}$ & $\begin{array}{l}\text { for different dimensions of particles can be applied in general } \\
\text { Usually } c_{1}=c_{2}=1.494 . \text { Other values can also be used, provided } \\
\text { that } 0<c_{1}+c_{2}<4 .\end{array}$ \\
\hline
\end{tabular}

Table 3. PSO convergence parameters [23]

\begin{tabular}{l}
\hline \multicolumn{1}{c}{ Description } \\
\hline $\begin{array}{l}\text { Maximum number of iterations }(t \max ) \text { for the termination } \\
\text { criterion }\end{array}$ \\
$\begin{array}{l}\text { Number of iterations }(\mathrm{kf}) \text { for which the relative } \\
\text { in conjunction with other PSO parameters }(n, N P)\end{array}$ \\
$\begin{array}{l}\text { improvement of the objective function satisfies the } \\
\text { convergence check }\end{array}$ \\
$\begin{array}{l}\text { Minimum relative improvement }(f m) \text { of the value of the } \\
\text { objective function }\end{array}$
\end{tabular}

\subsection{Proposed PSO Model}

Figure 2 displays the flow chart of the proposed PSO model utilized in the current study. The correct choice of the PSO parameters has a remarkable effect on the performance of the algorithm. These parameters are namely: swarm size, coefficient of inertia, and acceleration coefficient. The neighborhood size is also needed for the local best algorithm. 


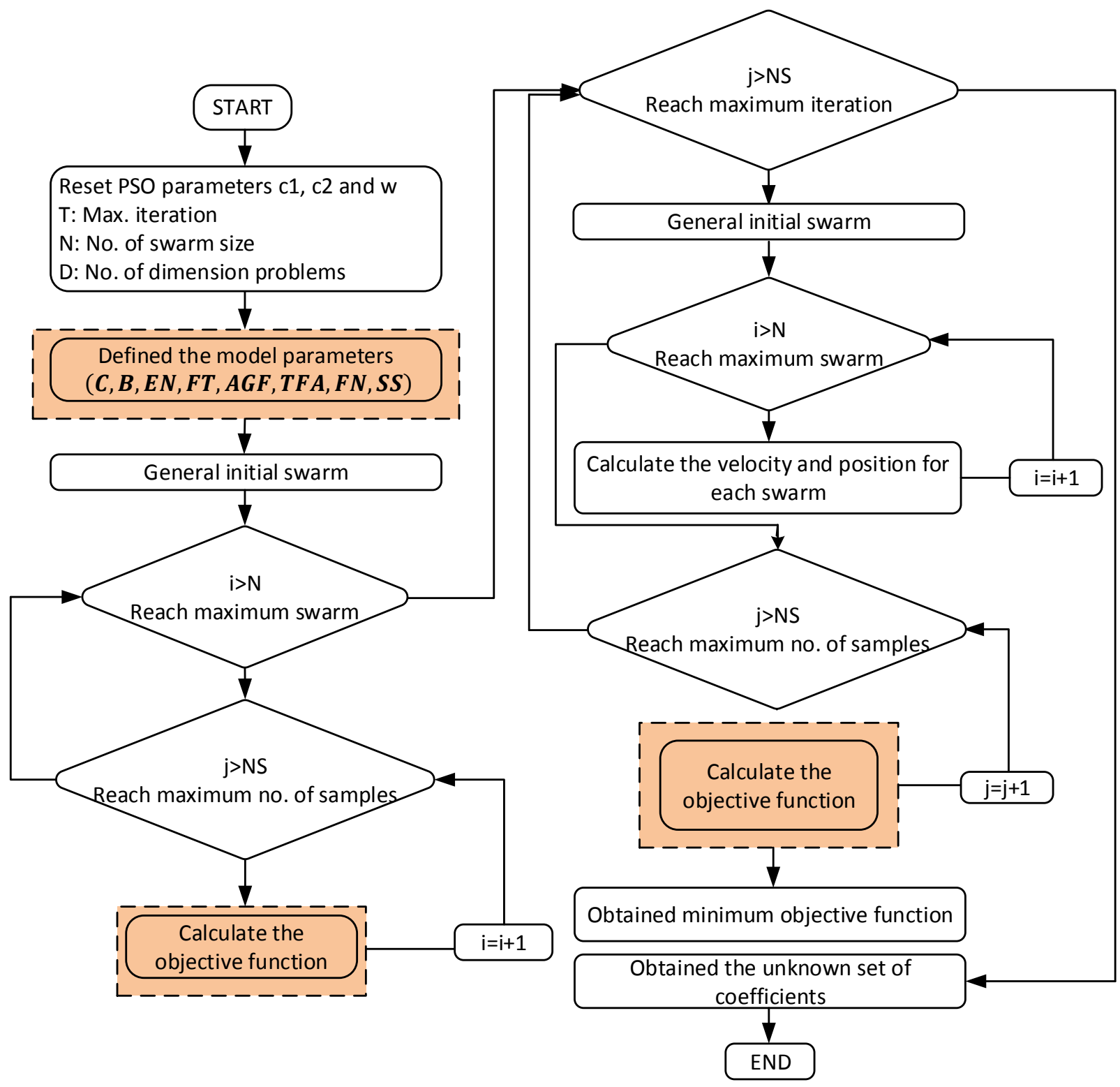

Figure 2. Flowchart of PSO of the proposed model

The optimization procedure typically uses a gradient-based algorithm appropriate for local exploration. Consequently, to be successful, the optimization procedure needs an initial point gotten from a global exploration. A strong training process requires both the initialization and optimization procedures. The following highlights how the PSO algorithm can be implemented to search for the optimum duration and cost amount of the construction projects.

- Create a swarm initialization by assigning a random location for each particle in the hyperspace problem.

- Evaluate the objective function of the proposed model for each particle.

- Compare the objective function value of each particle with pbest. If the current value is better than the pbest value, this value is set as pbest, and the position of the current particle, $X i$, is set to pbest.

- Identify particles with the best objective function value. The value of its target function is determined to be $g b e s t$, and its location is gbest.

- Update the velocity and the position of all particles based on Equations 3 and 4.

- Repeat steps 2-5 until the convergence criteria are met (the maximum number of iterations or a sufficient objective function value is obtained).

The proposed model was formulated utilizing MATLAB software to optimize the cost amount and duration models of construction projects. The proposed models to be optimized are as follows:

Cost $=F_{1}+F_{2} \cdot S S+F_{3} \cdot F N+F_{4} \cdot C+F_{5} \cdot B+F_{6} \cdot E N+F_{7} \cdot T A+F_{8} \cdot A G+F_{9} \cdot F T$ 
Duration $=K_{1}+K_{2} \cdot S S+K_{3} \cdot F N+K_{4} \cdot C+K_{5} \cdot B+K_{6} \cdot E N+K_{7} \cdot T A+K_{8} \cdot A G+K_{9} \cdot F T$

Where $F_{1}$ to $F_{9}$ and $K_{1}$ to $K_{9}$ are the unknown coefficients.

The main goal of utilizing PSO to optimize the cost amount and duration models is to examine for an optimum set of unknown coefficients. Hence, the difference between the actual cost amount of construction projects and that predicted utilizing the final form of the optimized expressions is minimal.

\subsection{Description of Dataset}

A total of 60 construction projects constructed by government contractors between 2008 and 2016 from different places in Iraq were collected. The selected projects (samples) represent about $80 \%$ of the projects implemented in Iraq in terms of implementation method, materials used, and architectural style. Eight input variables $(C, B, E N, F T$, $A G F, T F A, F N, S S)$ and two output variables (cost amount or duration), as displayed in Table 4.

Models inferred using optimization tools have the capability to estimate within the data range obtainable and are applied for additional development. Thus, the size of the dataset utilized for the modeling process is essential, as it impacts the accuracy of the final models. The behavior of any model modified using this data is influenced by the sample size and its variable distributions. Therefore, the data is graphically illustrated in Figure 3 as histograms. Figure 3 depicts the statistics of the samples utilized in constructing the proposed model.

For high accuracy, the ratio of the number of dataset records to the number of input parameters should not be less than three, as proposed by Frank and Todeschini (1994) [24], and they recommended to be higher than five. For the present case study, this ratio was $60 / 8=7.5$, which exceed the recommended criteria. From the 60 samples (projects), 48 samples $(80 \%)$ were considered for building the proposed models, while 12 samples $(20 \%)$ were utilized to validate the proposed models. The descriptive statistics of the dataset utilized in this study are given in Table 5.

Table 4. Input and Output Parameters

\begin{tabular}{|c|c|c|c|c|c|c|c|c|c|c|c|}
\hline Item & Project ID & SS & $\mathbf{F N}$ & $\mathbf{C}$ & B & $\mathbf{E N}$ & FT & AGF & GFA & Cost & Duration \\
\hline 1 & Building of Hajj and Umrah/ Anah/Anbar & 3 & 2 & 440 & 465 & 0 & 1 & 498 & 815 & 565.167 & 203 \\
\hline 2 & $\begin{array}{l}\text { Event hall of the Ebad al-Rahman mosque/ } \\
\text { Yusufiya / Baghdad }\end{array}$ & 1 & 1 & 155 & 108 & 0 & 1 & 402 & 320 & 177.765 & 95 \\
\hline 3 & $\begin{array}{l}\text { Secondary Sadiq Amin/ Muqdadiya/ } \\
\text { Diyala }\end{array}$ & 1 & 2 & 632 & 550 & 0 & 1 & 936 & 1610 & 844.313 & 204 \\
\hline 4 & $\begin{array}{l}\text { Secondary Amjad Al Zahawi/ Baquba/ } \\
\text { Diyala }\end{array}$ & 1 & 2 & 563 & 412 & 0 & 1 & 716 & 1210 & 665.824 & 186 \\
\hline 5 & $\begin{array}{l}\text { Secondary Prince Ali/ Tarmiyah/ suburb } \\
\text { of Baghdad }\end{array}$ & 3 & 2 & 612 & 638 & 0 & 1 & 833 & 1424 & 842.628 & 235 \\
\hline 6 & $\begin{array}{l}\text { Secondary of the last prophets/ } \\
\text { Yusufiya/Baghdad }\end{array}$ & 1 & 2 & 481 & 508 & 0 & 1 & 661 & 1110 & 581.117 & 182 \\
\hline 7 & School of Habib Ben Khedi/ Nineveh & 3 & 2 & 705 & 735 & 0 & 1 & 958 & 1650 & 1058.018 & 247 \\
\hline 8 & Abi Dardaa School/Kirkuk & 1 & 2 & 815 & 850 & 0 & 1 & 1095 & 1900 & 1032.063 & 217 \\
\hline 9 & $\begin{array}{l}\text { Falluja Islamic High } \\
\text { School/Fallujah/Anbar }\end{array}$ & 3 & 2 & 285 & 297 & 0 & 1 & 415 & 664 & 439.354 & 195 \\
\hline 10 & $\begin{array}{l}\text { Abu Ghraib secondary school/Abu } \\
\text { Ghraib/suburb of Baghdad }\end{array}$ & 2 & 2 & 571 & 590 & 0 & 1 & 782 & 1330 & 811.354 & 211 \\
\hline 11 & Apartments for health staff/Ramadi/Anbar & 3 & 1 & 312 & 220 & 0 & 1 & 765 & 650 & 495.48 & 134 \\
\hline 12 & $\begin{array}{l}\text { Secondary Al-Moatasem/ Samarra/Salah } \\
\text { al-Din }\end{array}$ & 3 & 2 & 653 & 615 & 0 & 1 & 1095 & 1900 & 662.535 & 261 \\
\hline 13 & $\begin{array}{l}\text { Residential Units for Employees/ Nukhayb } \\
\text { / Anbar }\end{array}$ & 3 & 2 & 98 & 140 & 0 & 1 & 239 & 344 & 237.018 & 177 \\
\hline
\end{tabular}




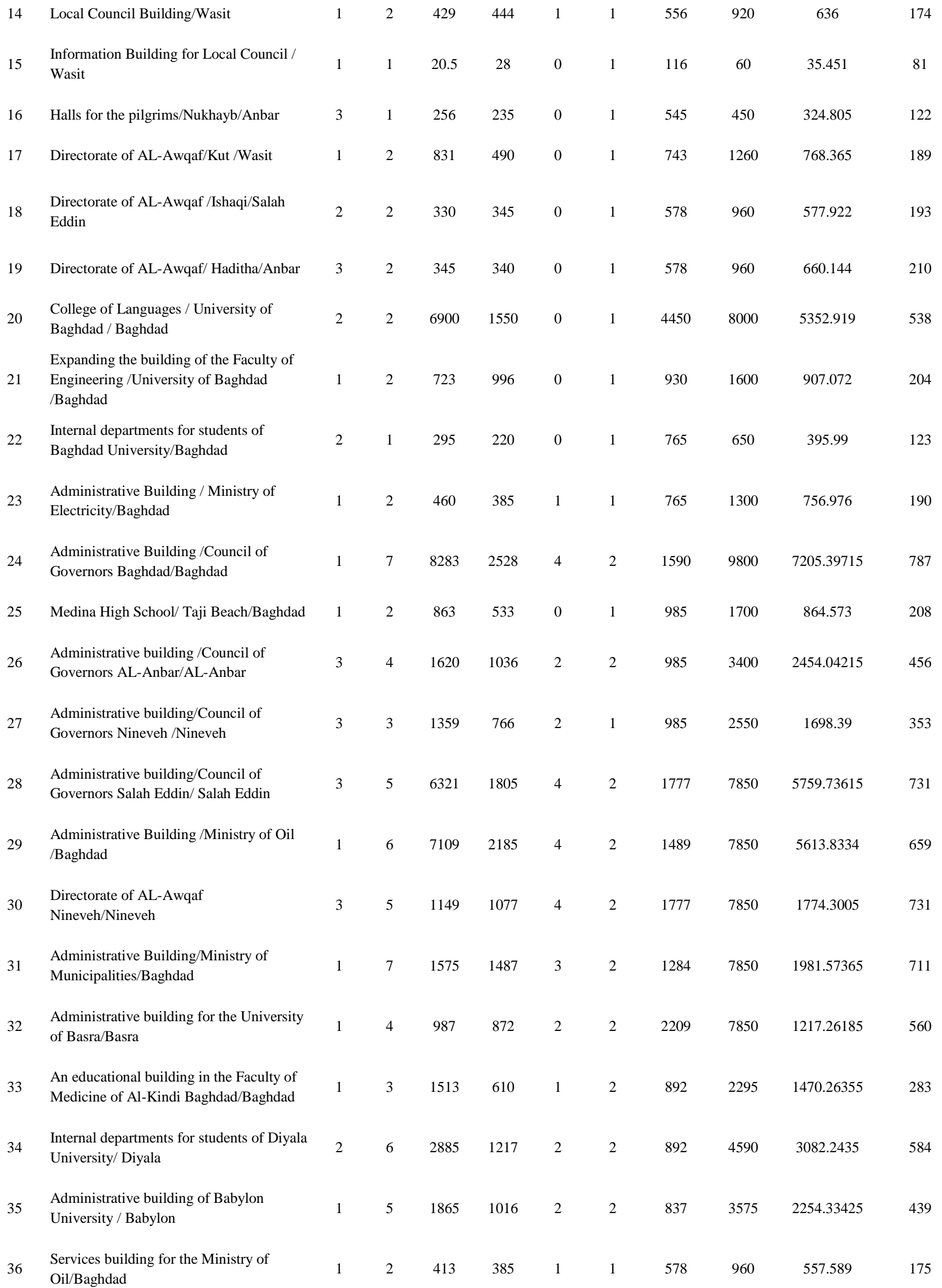


37
Administrative building of the Ministry of oil/Waest

Administrative building for the Ministry

of Labor and Social Affairs/Wasit

Administrative building of the Ministry of oil/ Salah Eddin

\section{Residential units for doctors/Baghdad \\ Immigration and Displaced Building/ \\ Wasit \\ Internal departments for students of \\ Baghdad University/Baghdad}

Administrative building of the Ministry of oil /Nineveh

\section{Directorate of AL-Awqaf /AL-Anbar \\ Internal departments for students of \\ University of Karbala/Karbala \\ Fatima Al - Zahra Secondary \\ School/Waset \\ Directorate of AL-Awqaf / Baghdad}

Administrative building of the Ministry of Finance/Baghdad

Administrative building of the Ministry of Interior

Internal sections for officers and security associates/Ministry of Interior / Baghdad

\section{Abdullah bin Rawahah School/Baghdad}

Administrative building of the Ministry of Interior/Baghdad

Administrative building of the Ministry of Interior/Kirkuk

Administrative building of the Ministry of Municipalities/Salah Eddin

Administrative building of the Ministry of Municipalities/AL-Anbar

Administrative building of the Ministry of Municipalities/Najaf

Administrative building of the Ministry of Municipalities/Babylon

Administrative building of the Ministry of Municipalitie / Ninava

Administrative building of the Ministry of Municipalities/ Wasit

Administrative building of the Ministry of Interior/Baghdad

2

1209

1088

2

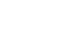

578

2880

1926.9201

2

1068

915

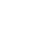

2

1495.8027

34928

13

717

1880

1392.3546

235

1140

1051

2730

1697.97495

302

4

1268

1415

2

710

1873.13385

321038

1196

1370

2400

3445.0983

4

24

1

5

2

709

1040

3600

2441.6721

3695.29965

42



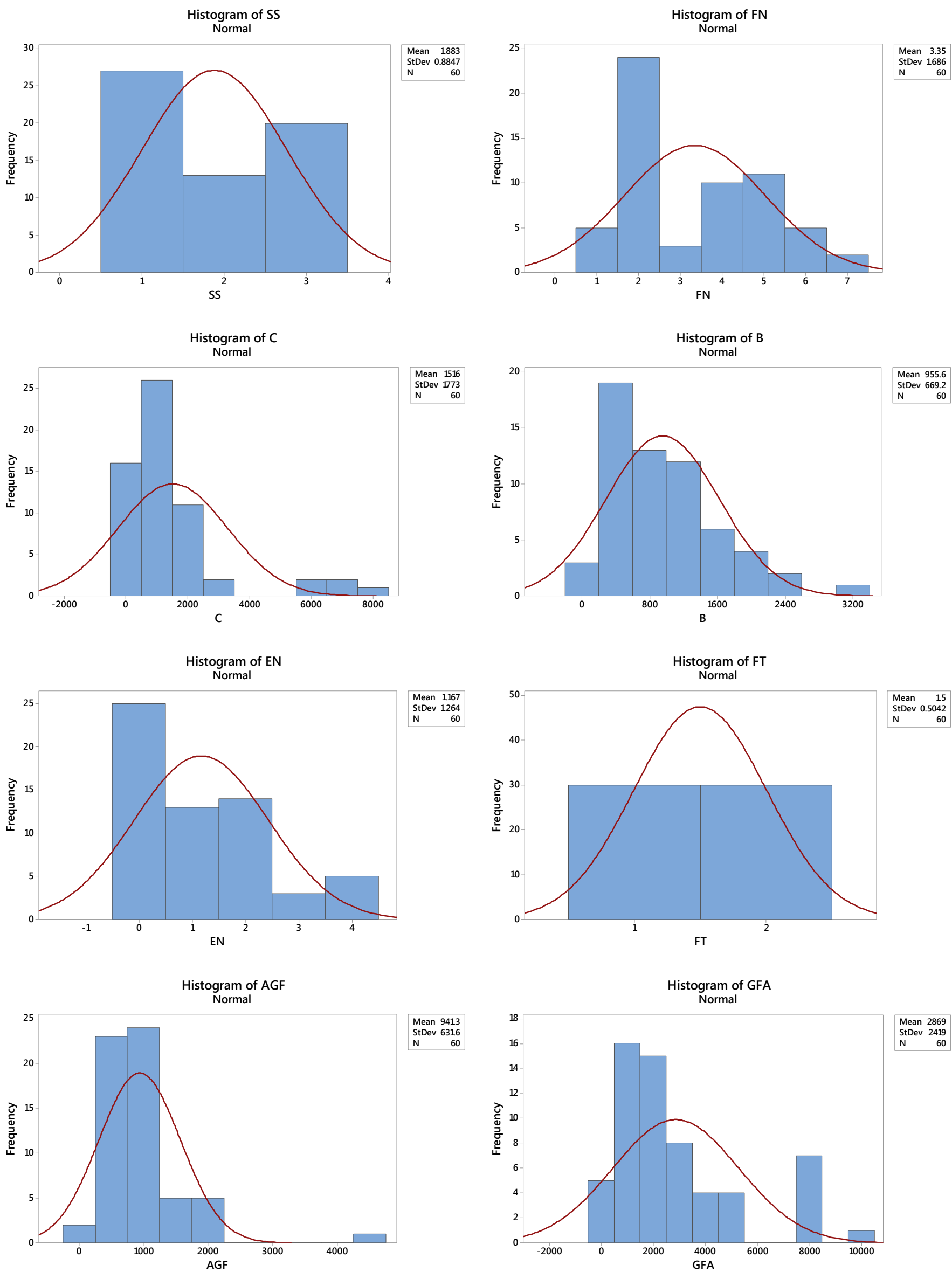

Figure 3. Histograms of independent input variables 
Table 5. Descriptive statistics of the variables used in the model development

\begin{tabular}{|c|c|c|c|c|c|c|}
\hline \multicolumn{2}{|c|}{ Description } & Mean & Standard Deviation & Range & Min. & Max. \\
\hline \multirow{8}{*}{ Input } & SS & 1.88 & 0.885 & 2 & 1 & 3 \\
\hline & $F N$ & 3.35 & 1.686 & 6 & 1 & 7 \\
\hline & $C$ & 1515.83 & 1773.455 & 8262.5 & 20.5 & 8283 \\
\hline & $B$ & 955.62 & 669.247 & 3287 & 28 & 3315 \\
\hline & $N O E$ & 1.167 & 1.2645 & 4 & 0 & 4 \\
\hline & $F T$ & 1.5 & 0.504 & 1 & 1 & 2 \\
\hline & $A G F$ & 941.27 & 631.60 & 4334 & 116 & 4450 \\
\hline & $G F A$ & 2869.47 & 2419.052 & 9740 & 60 & 9800 \\
\hline Output & Total-Cost & \multicolumn{5}{|c|}{ Total cost/duration of construction projects } \\
\hline
\end{tabular}

\section{Results and Discussion}

The PSO technique was utilized to optimize the construction projects cost and-or duration amount. Models have been proposed to examine the influences of swarm size on the outcomes. The main job of the objective function in a PSO approach is to reduce the difference between the predicted and actual cost and/or duration amount. PSO offers models that can assess the cost and-or duration and finding results as close as possible to the measured results. The PSO technique updates its process until either a proper global best (gbest) or the maximum epochs (iterations) is achieved, as presented in the methodology. Table 6 shows the parameters used in the PSO model.

Table 6. Parameters of the PSO

\begin{tabular}{cc}
\hline Parameters & Values \\
\hline Swarm size & $10,20,30,40$, and 50 \\
Target error & $1 \mathrm{e}-05$ \\
Iteration & 10000 \\
$C_{1}$ & 1.495 \\
$C_{2}$ & 1.495 \\
$w$ & 0.7 \\
\hline
\end{tabular}

Statistical methods, namely: the coefficient of variation (CoV), correlation coefficient (R), and Bland-Altman (2007) [25] analysis, were used in this study to evaluate and examine the ability of the proposed models. The root mean square error (RMSE) was used as an objective function to choose unknown coefficients. Additionally, five swarm sizes (10, $20,30,40$, and 50) were used and evaluated. In this study, the iterations number fixed to 1000 because of the differences in the objective functions are stabilized after 700 iterations, as shown in Figure 4 for both cost and duration models. Numerous swarm sizes were tested to evaluate which swarms could minimize the error.

Cost model

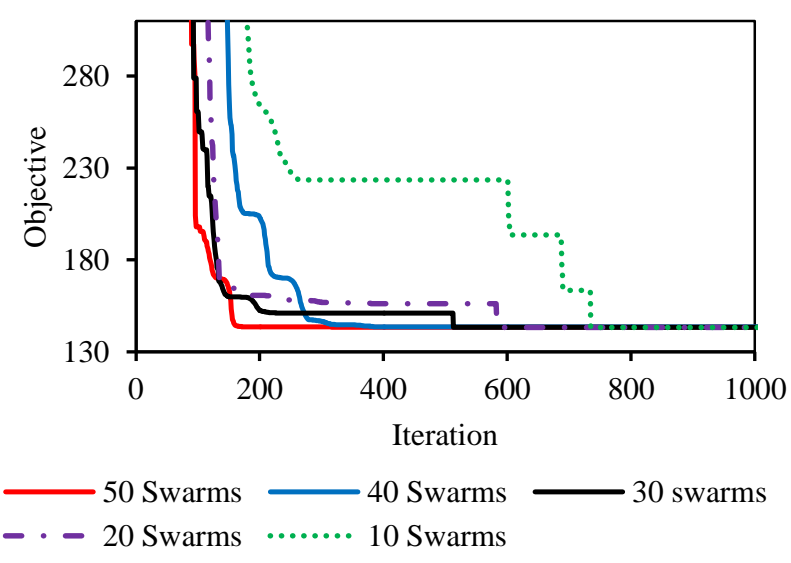

Duration model

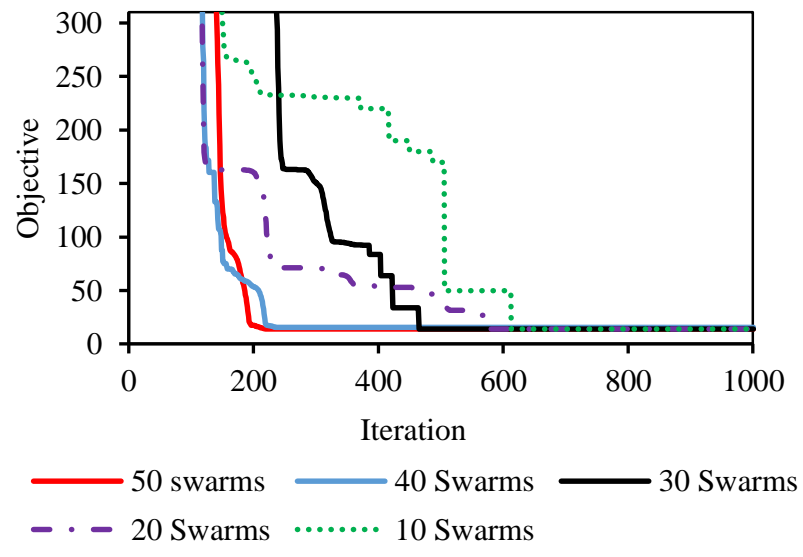

Figure 4. Objective function (RMSE) versus iteration. 
The Bland-Altman (2007) [25] approach was applied to check the agreement between the actual (A) and predicted (B) cost/duration. The difference between the actual and estimated cost/duration $(\mathrm{A}-\mathrm{B})$ is plotted against their mean value $((A+B) / 2)$, as presented in Figure 5. The Bland-Altman plot exposes the variances in the results and presentations the systematic and random variances. The average value $(\mathrm{m})$ of +1.96 and standard deviation (SD) of -1.96 are displayed in the diagram. These values are called the "limits of agreement". Such limits of agreement specify whether the limits are large or small concerning the overall values, where values outside these ranges show low accuracy.
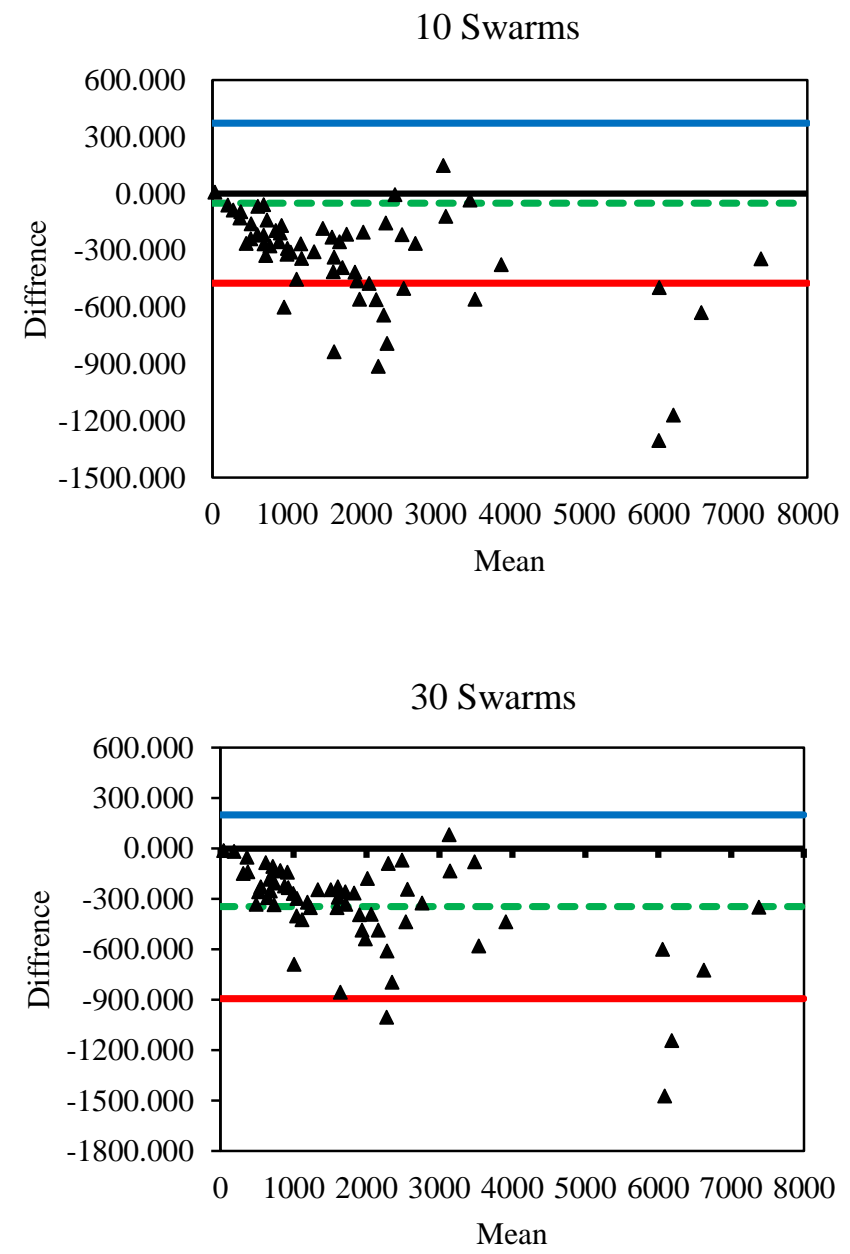
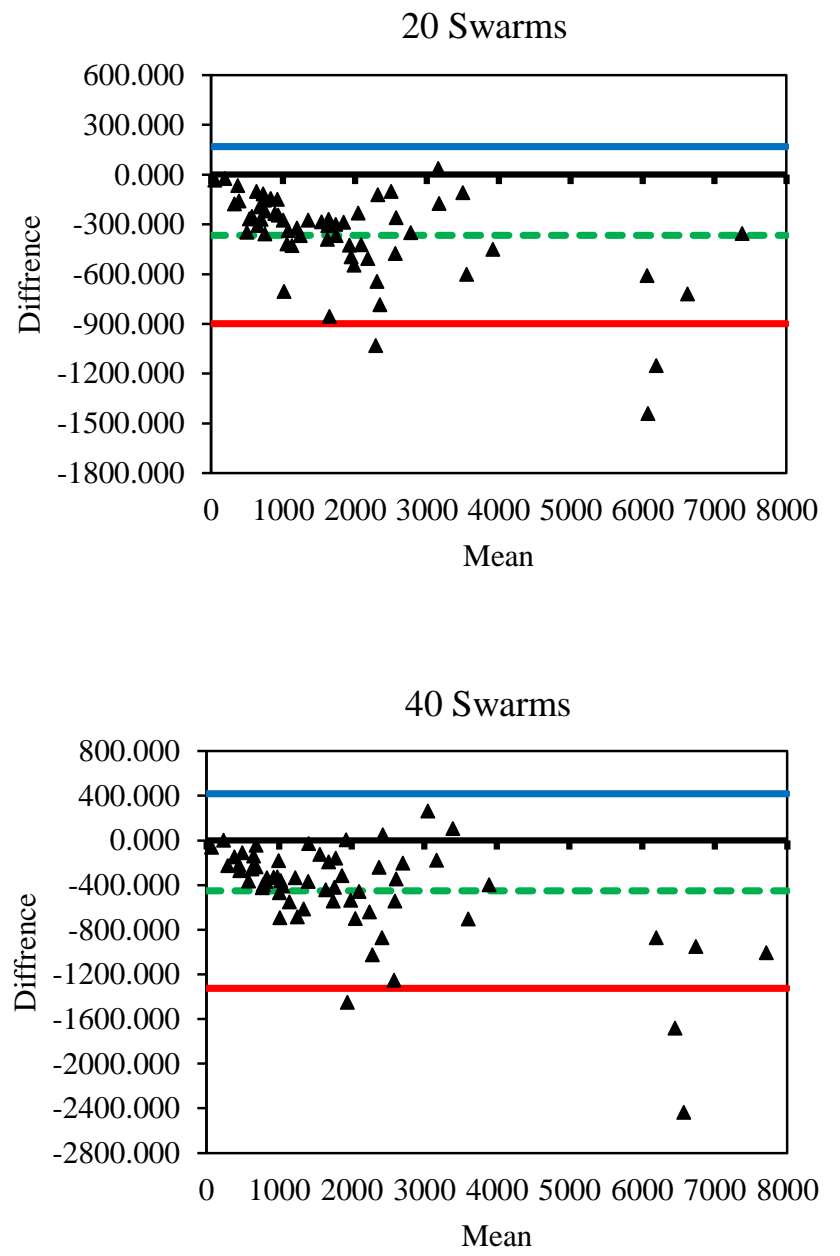

50 Swarms

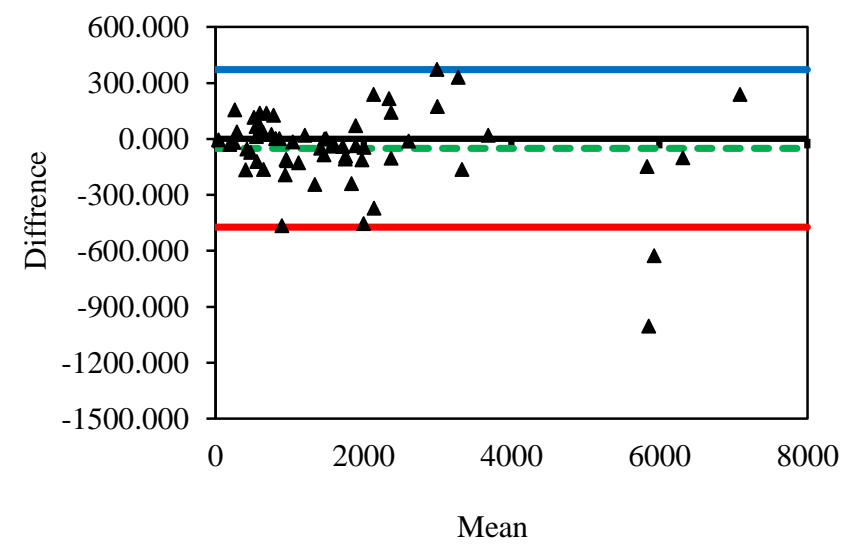

a) Cost model 
10 Swarms

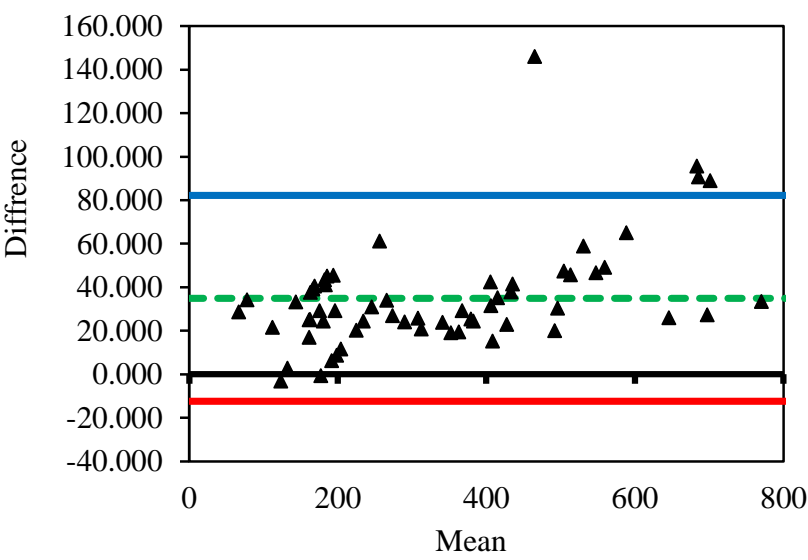

30 Swarms

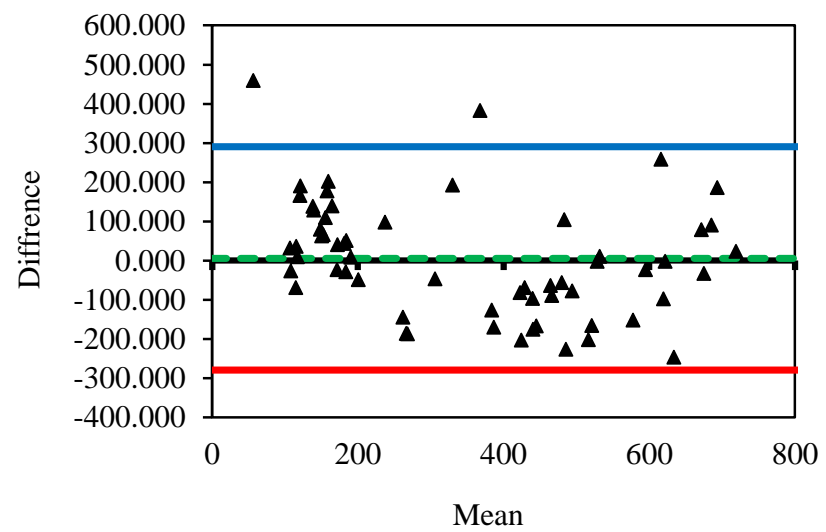

20 Swarms

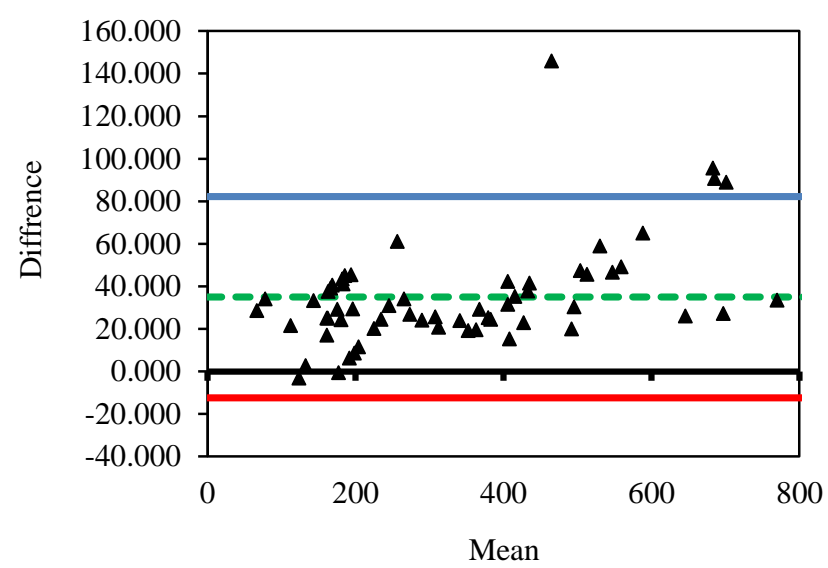

40 Swarms

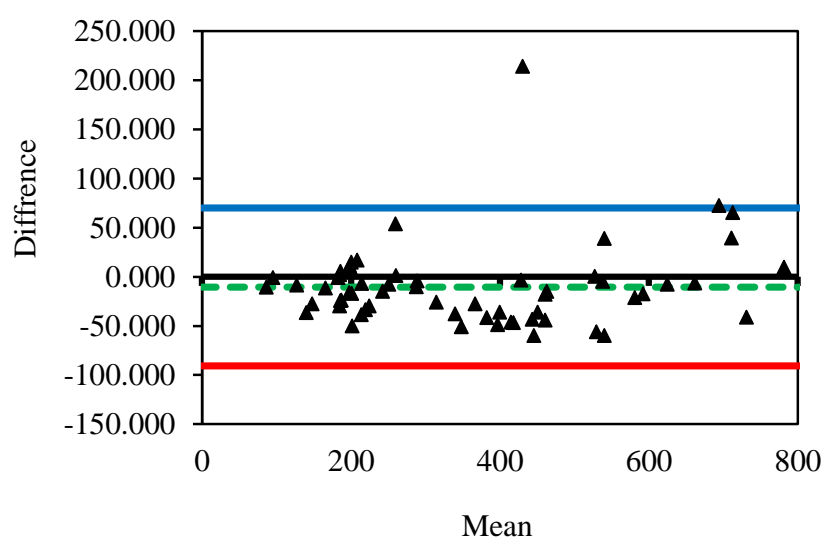

50 Swarms

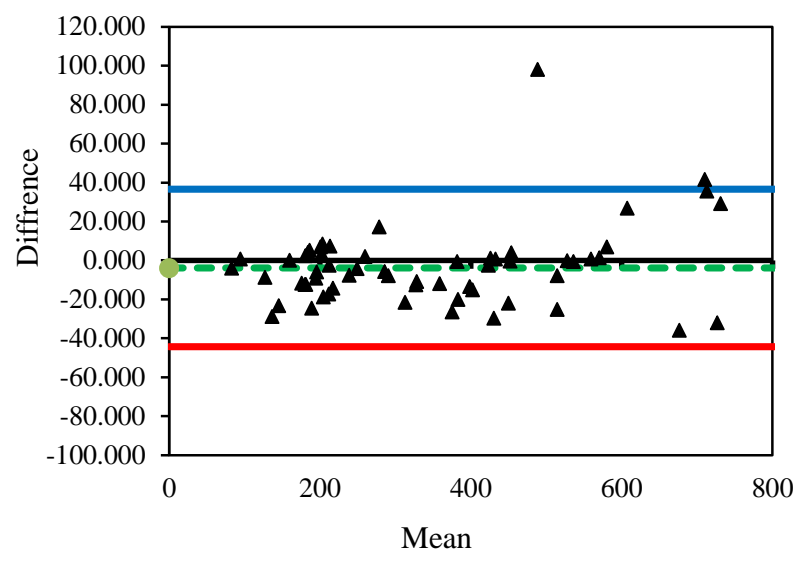

b) Duration model

Figure 5. Bland-Altman plot of the relationship between actual and predicted cost and duration values for $\mathbf{5 0}$ swarms

As previously determined, Bland-Altman analysis predicts the level of difference. Monitoring scattered values can help to find agreement between actual and predicted values. As shown in Figure 5, a reasonable agreement between the test methods was presented. This figure shows that the data is distributed within the limits of the agreement, indicating the appropriate accuracy of the proposed models. Figure 4 illustrations that 50 swarms provided a better solution for the PSO because, they accomplished the minimum objective functions with $95.83 \%$ and $97.92 \%$ accuracy, for cost and duration, respectively. With respect to the other swarm sizes, 10 swarms produced significant errors. The results show that the 50 swarms displayed a higher accuracy for the actual values for both models, namely: cost and duration. 
According to the $\mathrm{CoV}$ and $R$ values, the proposed models accomplish minimum error, as presented in Table 7 . The best solution for the PSO algorithm because it accomplishes a minimum coefficient of variation, CoV, and maximum value of correlation coefficient $(R)$, as presented in Table 7. Smith (1986) [26] recommended a rational hypothesis to judge the performance of the model by the following criteria:

- If a model gives $|R|>0.8$, a strong correlation occurs between the forecast and actual values;

- If a model gives $0.2<|R|<0.8$, a good correlation occurs between the forecast and actual values;

- If a model gives $|R|<0.2$, a weak correlation occurs between the forecast and actual values.

Figure 6 displays that the proposed PSO models had an adequate R-values ( 0.9441 and 0.9940 for cost and duration) and assessed the target values with adequate accuracy. Moreover, the coefficients $\left(F_{1}\right.$ to $\left.F_{9}\right)$ and $\left(K_{1}\right.$ to $\left.K_{9}\right)$ obtained from the optimization results will be substituted in Eqs. 5 and 6 of the proposed models, as presented in the following final expressions.

$$
\begin{gathered}
\text { Cost }=-611.346+156.283 \cdot S S+83.98399 \cdot F N+0.610803 \cdot C+0.567313 \cdot B+92.57055 \cdot E N-0.16582 \\
\cdot T A+0.610803 \cdot A G+0.567313 \cdot F T \\
\text { Duration }=2.903068+25.6335 \cdot S S+54.38925 \cdot F N-0.00249 \cdot C+0.009338 \cdot B+13.94593 \cdot E N \\
+0.036325 \cdot T A+0.00249 \cdot A G+0.009338 \cdot F T
\end{gathered}
$$

Table 7. Factors used in the PSO-Cost and PSO-duration models setting

\begin{tabular}{ccccc}
\hline & PSO-Cost & & PSO- Duration \\
\cline { 2 - 3 } Factor & 50 Swarm & & Factor & 50 Swarm \\
\hline F 1 & -611.346 & & K 1 & 2.903068 \\
F 2 & 156.283 & & K 2 & 25.6335 \\
F 3 & 83.98399 & & K 3 & 54.38925 \\
F 4 & 0.610803 & K 4 & -0.00249 \\
F 5 & 0.567313 & K 5 & 0.009338 \\
F 6 & 92.57055 & K 6 & 13.94593 \\
F 7 & -0.16582 & K 7 & 0.036325 \\
F 8 & 0.610803 & K 8 & -0.00249 \\
F 9 & 0.567313 & K 9 & 0.009338 \\
\hline M & 0.988 & & 0.981 \\
SD & 0.174 & 17.6 & & 0.058 \\
COV \% & 0.9441 & & 9.0 \\
R & & & 0.9940 \\
\hline
\end{tabular}
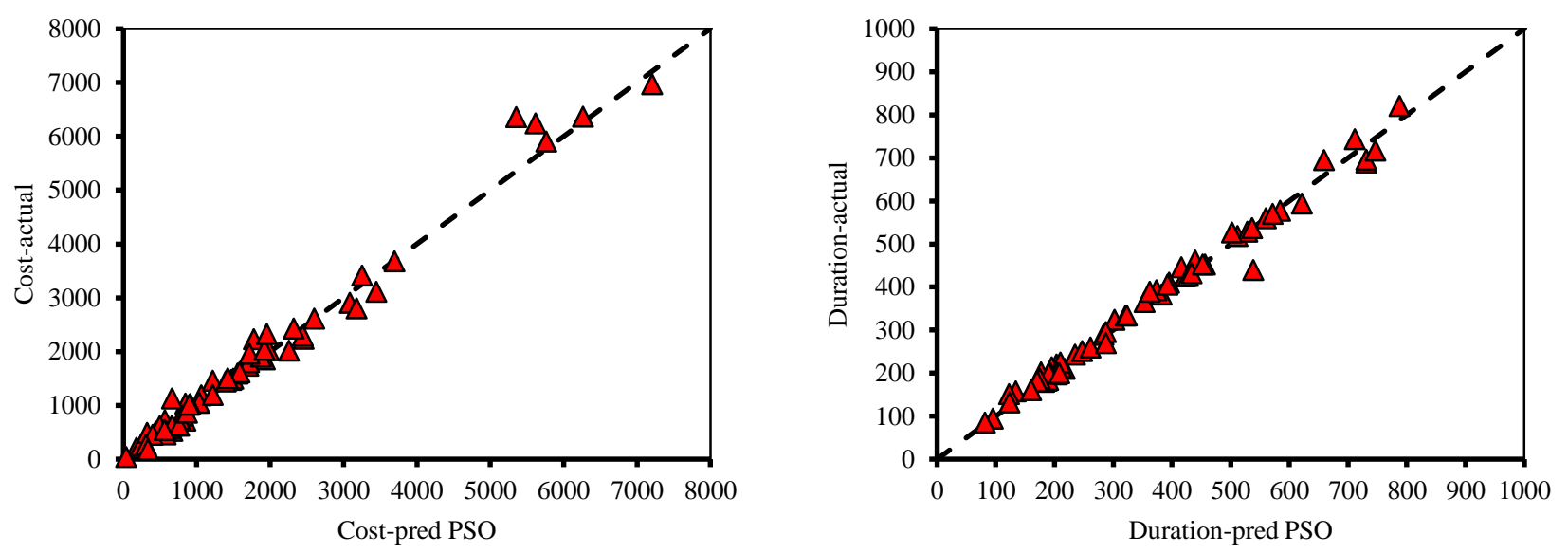

Figure 6. Predicted vs. actual cost and duration values using the proposed model 


\section{The Validity of the Proposed Models}

A dataset comprising of 12 construction projects (20\% of the total dataset) was utilized to examine and validate the proposed models. These samples were not utilized in the construction stage of the proposed models. Table 8 shows that the cost and duration assessed by the proposed models are reliable and consistent based on the results. The results recorded values of the mean close to 1.0 (0.97 and 0.99 for cost and duration); this reflected the accuracy of the proposed model, as presented in Table 8.

Pimentel-Gomes (2000) [27] specified that the value of a CoV reflects the accuracy of the relationship between the inputs and the output, where $\mathrm{CoV}$ values of less than 10\%, 20-30\%, and above 30\% mean high accuracy, low accuracy, and low precision, respectively. For the proposed model, the COVs for cost and duration models were $10.86 \%$ and $4.93 \%$, representing high accuracy. Moreover, the $R$-values of 0.9914 and 0.9940 (as presented in Table 8 ) reflect a good agreement between the actual and forecast cost and duration values. It can be stated based on these results that the proposed models efficiently assess the cost and duration of the construction projects.

Table 8. Actual database and values predicted using the PSO model

\begin{tabular}{|c|c|c|c|c|c|c|c|}
\hline Item & Project ID & $\begin{array}{l}\text { Cost } \\
\text { actual }\end{array}$ & $\begin{array}{l}\text { Duration } \\
\text { actual }\end{array}$ & PSO-Cost & $\begin{array}{l}\text { Cost } \\
\text { Actual/predicted }\end{array}$ & $\begin{array}{l}\text { PSO } \\
\text { Duration }\end{array}$ & $\begin{array}{l}\text { Duration } \\
\text { Actual/predicted }\end{array}$ \\
\hline 1 & $\begin{array}{l}\text { Event hall of the Ebad al-Rahman mosque / } \\
\text { Yusufiya / Baghdad }\end{array}$ & 177.765 & 95 & 207.6 & 0.86 & 94.2 & 1.01 \\
\hline 2 & School of Habib Ben Khedi/ Nineveh & 1058.018 & 247 & 1185.2 & 0.89 & 251.3 & 0.98 \\
\hline 3 & $\begin{array}{l}\text { Residential Units for Employees/ Nukhayb } \\
\text { /Anbar }\end{array}$ & 237.018 & 177 & 254.3 & 0.93 & 201.6 & 0.88 \\
\hline 4 & Directorate of AL-Awqaf/Kut/ Wasit & 768.365 & 189 & 743.9 & 1.03 & 183.8 & 1.03 \\
\hline 5 & $\begin{array}{l}\text { Expanding the building of the Faculty of } \\
\text { Engineering/University of Baghdad / Baghdad }\end{array}$ & 907.072 & 204 & 1022.9 & 0.89 & 200.6 & 1.02 \\
\hline 6 & $\begin{array}{l}\text { Administrative building/Council of Governors } \\
\text { AL-Anbar /AL-Anbar }\end{array}$ & 2454.04215 & 456 & 2238.2 & 1.10 & 452.0 & 1.01 \\
\hline 7 & $\begin{array}{l}\text { Administrative building of Babylon } \\
\text { University/Babylon }\end{array}$ & 2254.33425 & 439 & 2015.1 & 1.12 & 461.0 & 0.95 \\
\hline 8 & $\begin{array}{l}\text { Administrative building for the Ministry of } \\
\text { Labor and Social Affair /Waset }\end{array}$ & 1495.8027 & 422 & 1493.6 & 1.01 & 424.6 & 0.99 \\
\hline 9 & $\begin{array}{l}\text { Administrative building of the Ministry of oil/ } \\
\text { Nineveh }\end{array}$ & 1715.766 & 287 & 1955.4 & 0.88 & 294.9 & 0.97 \\
\hline 10 & Directorate of AL-Awqaf / Baghdad & 1554.1911 & 395 & 1591.8 & 0.98 & 410.2 & 0.96 \\
\hline 11 & $\begin{array}{l}\text { Internal sections for officers and security } \\
\text { associates/Ministry of Interior / Baghdad }\end{array}$ & 1956.013 & 287 & 2327.8 & 0.84 & 269.8 & 1.06 \\
\hline \multirow[t]{5}{*}{12} & $\begin{array}{l}\text { Administrative Building of the Ministry of } \\
\text { Municipalities/AL-Anbar }\end{array}$ & 3177.9678 & 621 & 2806 & 1.13 & 594.1 & 1.05 \\
\hline & & & M & & 0.97 & & 0.99 \\
\hline & & & SD & & 0.105 & & 0.049 \\
\hline & & & $\mathrm{CoV} \%$ & & 10.86 & & 4.93 \\
\hline & & & $\mathrm{R}$ & & 0.9914 & & 0.9940 \\
\hline
\end{tabular}

The criteria suggested by Golbraikh et al. (2002) [28] were checked for the external verification of the proposed models on the testing datasets. It seems that at least one slope of regression lines ( $k$ or $\left.k^{\prime}\right)$ through the origin should be close to 1.0. Roy and Roy (2008) [29] introduced a confirmative indicator of the external predictability of models $\left(R_{m}\right)$. For $R_{m}>0.5$, the condition is satisfied. The squared correlation coefficient (through the origin) between predicted and experimental values $\left(R_{o}^{2}\right)$ should be close to 1 .

The considered validation criteria and the relevant results obtained by the model are presented in Table 9. As can be seen, the proposed models satisfy the required conditions. The external validation criteria result for the models are presented in Table 9. 
Table 9. Statistical parameters of the PSO models for external validation

\begin{tabular}{|c|c|c|c|c|}
\hline Item & Formula & Condition & Cost model & Duration model \\
\hline \multirow[b]{2}{*}{1} & $R=\frac{\sum_{i=1}^{n}\left(E A_{i}-\overline{E A_{l}}\right)\left(E E_{i}-\overline{E E_{l}}\right)}{2}$ & & & \\
\hline & $R=\frac{\sqrt{\sum_{i=1}^{n}\left(E A_{i}-\overline{E A_{l}}\right)^{2}} \sum_{i=1}^{n}\left(E E_{i}-\overline{E E_{l}}\right)^{2}}{2}$ & $R>0.8$ & 0.9914 & 0.9940 \\
\hline 2 & $k=\frac{\sum_{i=1}^{n}\left(E A_{i} \times E E_{i}\right)}{E A_{i}^{2}}$ & $0.85<k<1.15$ & 1.0592 & 1.0340 \\
\hline 3 & $k 1=\frac{\sum_{i=1}^{n}\left(E A_{i} \times E E_{i}\right)}{E E_{i}^{2}}$ & $0.85<k 1<1.15$ & 0.9441 & 0.9671 \\
\hline 4 & $R_{m}=R^{2} \times\left(1-\sqrt{\left|R^{2}-R_{o}^{2}\right|}\right)$ & $R_{m}>0.5$ & 0.8690 & 0.7858 \\
\hline where & $R_{o}^{2}=1-\frac{\sum_{i=1}^{n}\left(E E_{i}-E A_{i}^{o}\right)^{2}}{\left(E E_{i}-\overline{E E_{l}}\right)^{2}}, \quad E A_{i}^{o}=k \times E E_{i}$ & & & \\
\hline
\end{tabular}

The cost and duration values estimation achieved by the proposed models are illustrated in Figures 7 and 8 . The models have acceptable estimation accuracy when the ratio of the actual to estimated values is close to one. As can be presented from Figure 7, the ratio distribution of the actual to estimate values for the proposed PSO model in duration have better estimation accuracy than the PSO model in cost.

For further statistical analysis for the mentioned models, a comparison between the actual and assessed cost and duration values has been illustrated in Figure 8. This Figure shows that the proposed PSO model in the duration is closer to the actual duration of projects than the proposed PSO model in cost.
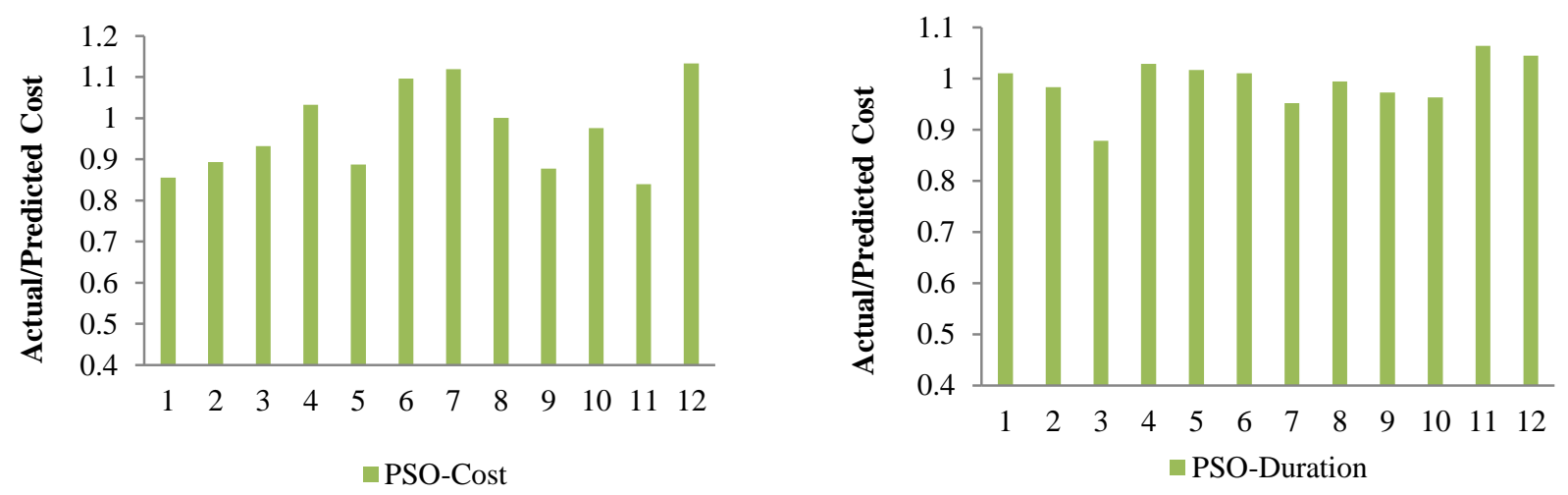

Figure 7. Comparison between the predicted and actual cost and duration amount using the PSO models
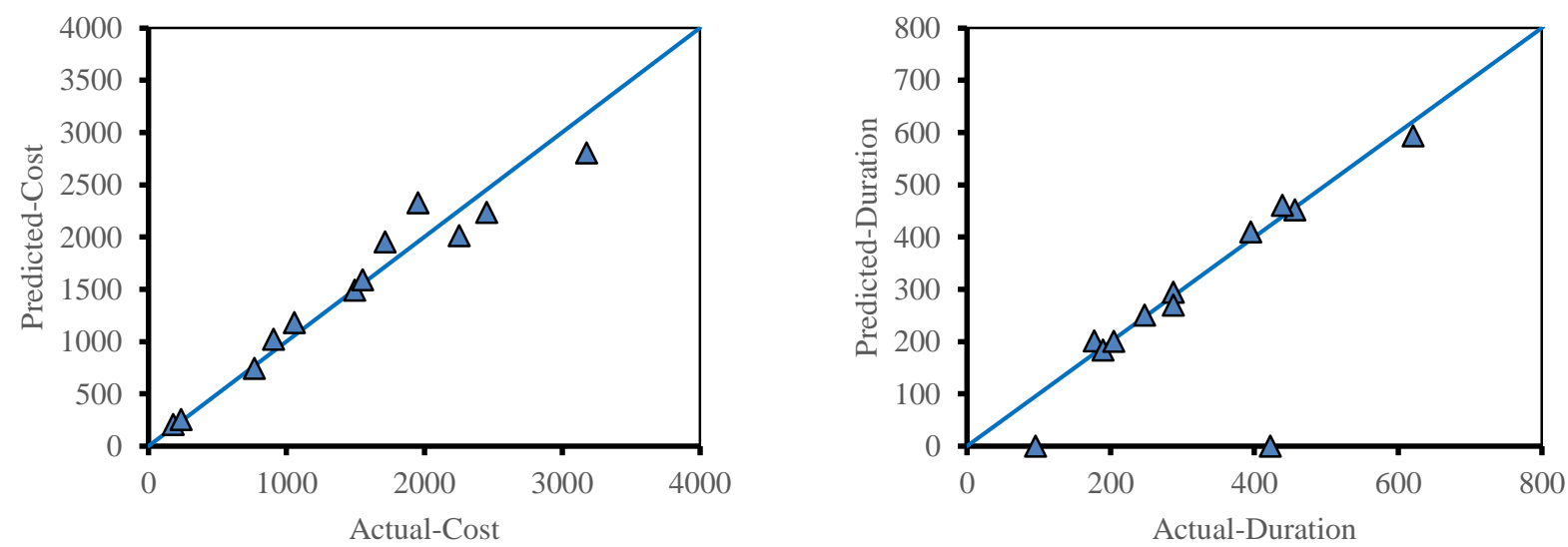

Figure 8. Actual versus predicted cost and duration amount utilizing the PSO models

\section{Screening and Parametric Analyses}

After constructing the proposed model, various phases were considered: (i) deriving the final models based on collected datasets; (ii) computing several external validation criteria to verify the models; and (iii) conducting a parametric study based on engineering principles and the physics of the problem. The first two steps are purely statistical; 
however, the third step is based on engineering principles and should be performed by an engineer who understands the problem being modeled. The first and second steps were achieved here for this type of problem. Therefore, for further verification of the developed model of cost and duration value, a parametric analysis was performed.

This study primarily seeks to assess the effect of individual parameters on cost and duration values. Figure 9 demonstrations the forecast values of the cos and duration accomplished by the proposed models as a function of each parameter. Figure 9 (a) and (b) show the proposed models as a function of the $(C, B, E N, F T, A G F, T F A, F N, S S)$ parameters. Figure 9 (a) and (b) display that increases in the amounts of $C, B, E N, F T, A G F, T F A, F N, S S$ up to a certain level lead to increases in the cost and duration values, indicating that the proposed models can be utilized as a guide to choose the suitable parameters correctly. Moreover, Figure 9 displays that the parameters SS, C, and GFA are the most effect parameters on the cost and duration values.

\section{Pareto Chart of the Effects (response is Duration, $\alpha=0.05$, only 30 effects shown)}

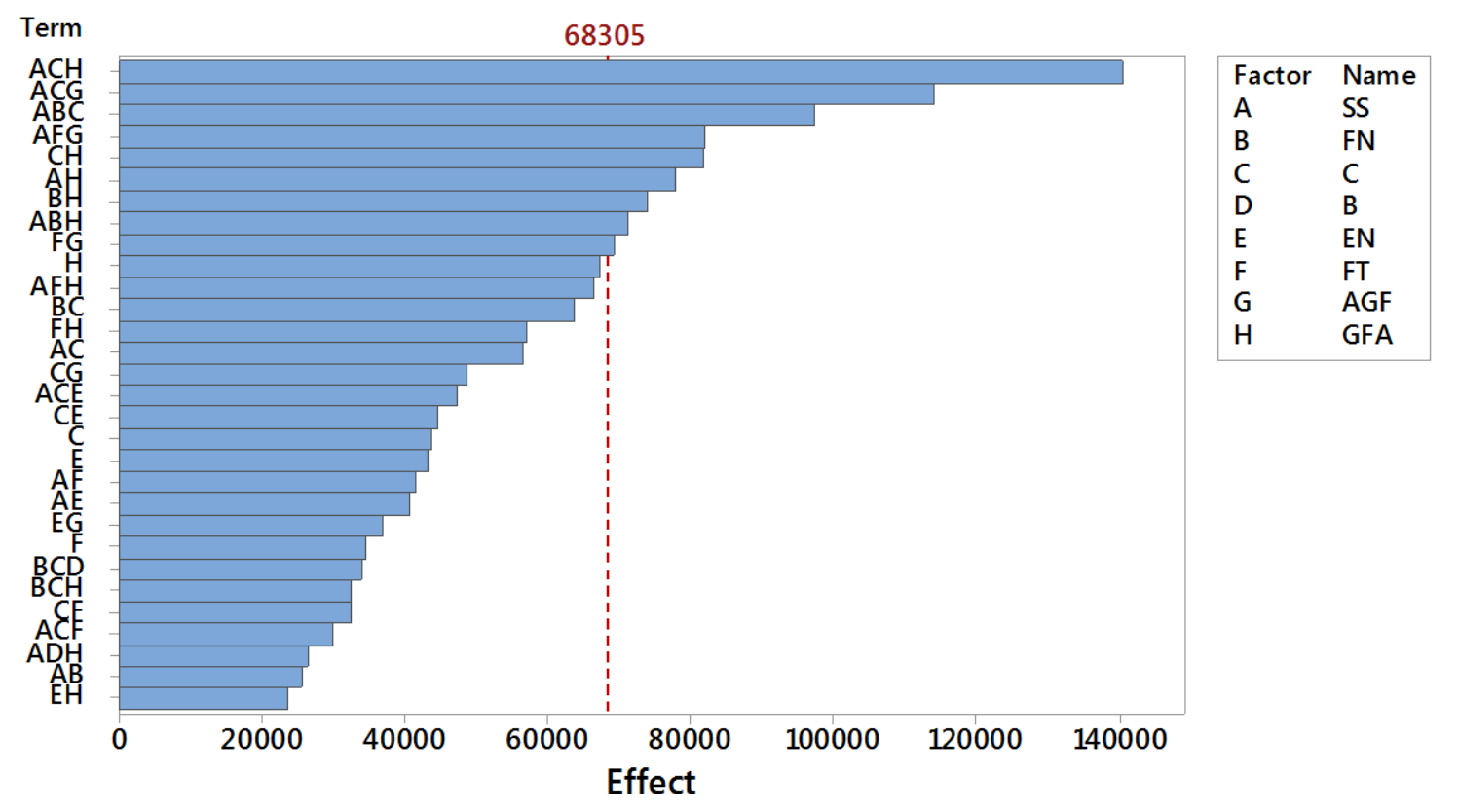

(a) Duration model

\section{Pareto Chart of the Effects \\ (response is Cost, $\alpha=0.05$, only 30 effects shown)}

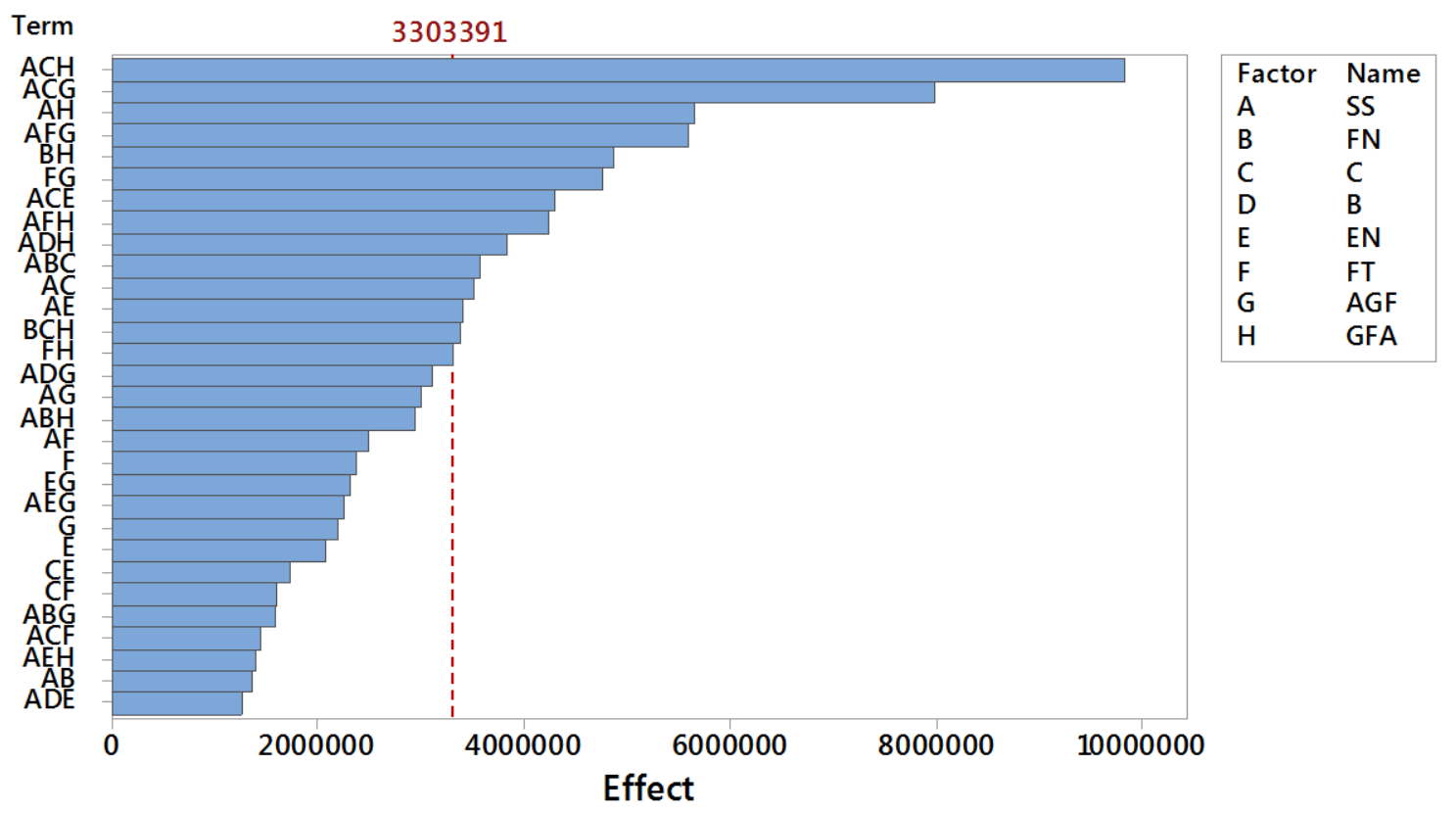

(b) Cost model

Figure 9 Parametric analysis of the cost and duration values using the proposed models 


\section{Conclusions and Recommendations}

The main objective of this study was to develop mathematical models that will be applied to forecast the cost and duration of the construction projects. In this study, sixty construction projects were utilized to build the proposed models at early-stage design. The main conclusions are drawn according to the models' outcomes, as follows:

- The contractors can utilize the proposed model to assess the construction cost and/or duration, and compare them with that specified by the client at the bid phase, to know if the cost and/or duration will be reasonable for the given project and its budget. This modeling technique based on historical datasets collected from existing projects. Thus, it is more practical, consistent, and reliable than currently utilized subjective methods based on intuitive assessments by designers.

- The statistical analysis demonstrations that the $C o V$, mean, and $R$ display good accuracy and reliability for the predicted values. With low mean (0.97 and 0.99$)$ and $\operatorname{CoV}(10.87 \%$ and $4.94 \%)$ values, the proposed PSO models (for both cost and duration) provide a proper assessment of the construction projects. Hence, this model can be utilized as a design indicator of cost and duration estimations at the early-stage design.

- The outcomes display that the PSO technique is proper for evaluating project management problems and can be utilized as a useful tool to search the optimal solutions with differs parameters.

- The proposed model supplies a guide for choosing the suitable parameters that influence the cost and duration parameters, such as security status, total area, area of the ground floor, floors number, the brick and concrete volume, and elevators number.

In this study, the dataset for only sixty construction projects was utilized to build the model. Nevertheless, more case studies with similar kinds of projects will supply more consistent results.

- Further construction projects should be conducted to examine and modify the proposed model and to investigate a wide range of parameters.

- Future research could be considered to build a model for cost and/or duration estimation for green buildings.

\section{Conflicts of Interest}

The authors declare no conflict of interest.

\section{References}

[1] Foussier, Pierre Marie Maurice. From Product Description to Cost: A Practical Approach: Volume 1: The Parametric Approach. Springer Science \& Business Media, (2006).

[2] Layer, Alexander, Erik Ten Brinke, Fred Van Houten, Hubert Kals, and Siegmar Haasis. "Recent and Future Trends in Cost Estimation." International Journal of Computer Integrated Manufacturing 15, no. 6 (January 2002): 499-510. doi:10.1080/09511920210143372.

[3] Rardin, Ronald L., and Ronald L. Rardin. Optimization in operations research. Vol. 166. Upper Saddle River, NJ: Prentice Hall, (1998).

[4] Chinneck, John W. "Practical optimization: a gentle introduction." Systems and Computer Engineering), Carleton University, Ottawa, (2006). Available online: http://www.sce.carleton.ca/faculty/chinneck/po.html.

[5] Van Den Bergh, Frans. "An analysis of particle swarm optimizers." PhD diss., University of Pretoria, (2007).

[6] Bromilow, F. J. "Measurement and scheduling of construction time and cost performance in the building industry." The Chartered Builder 10, no. 9 (1974): 57-65.

[7] Carr, Robert I. "Simulation of construction project duration." Journal of the Construction Division 105, no. 2 (1979): 117-128.

[8] Wang, Yu-Ren, Chung-Ying Yu, and Hsun-Hsi Chan. "Predicting Construction Cost and Schedule Success Using Artificial Neural Networks Ensemble and Support Vector Machines Classification Models.” International Journal of Project Management 30, no. 4 (May 2012): 470-478. doi:10.1016/j.ijproman.2011.09.002.

[9] Hong, Yuan, Haibo Liao, and Yazhi Jiang. "Construction Engineering Cost Evaluation Model and Application Based on RSIPSO-BP Neural Network.” Journal of Computers 9, no. 4 (April 1, 2014). doi:10.4304/jcp.9.4.1020-1025.

[10] Zima, Krzysztof. “The Case-Based Reasoning Model of Cost Estimation at the Preliminary Stage of a Construction Project." Procedia Engineering 122 (2015): 57-64. doi:10.1016/j.proeng.2015.10.007. 
[11] Lee, Dongoun, Seungho Kim, and Sangyong Kim. "Development of Hybrid Model for Estimating Construction Waste for Multifamily Residential Buildings Using Artificial Neural Networks and Ant Colony Optimization.” Sustainability 8, no. 9 (September 1, 2016): 870. doi:10.3390/su8090870.

[12] Juszczyk, Michał, Agnieszka Leśniak, and Krzysztof Zima. "ANN Based Approach for Estimation of Construction Costs of Sports Fields.” Complexity 2018 (2018): 1-11. doi:10.1155/2018/7952434.

[13] Hegazy, T_, P. Fazio, and O. Moselhi. "Developing practical neural network applications using back - propagation." Computer - Aided Civil and Infrastructure Engineering 9, no. 2 (1994): 145-159. doi:10.1111/j.1467-8667.1994.tb00369.x.

[14] Hanoon, Ammar N., M. S. Jaafar, Farzad Hejazi, and Farah N.A. Abdul Aziz. "Energy Absorption Evaluation of Reinforced Concrete Beams Under Various Loading Rates Based on Particle Swarm Optimization Technique.” Engineering Optimization 49, no. 9 (December 2016): 1483-1501. doi:10.1080/0305215x.2016.1256729.

[15] Hanoon, Ammar N., M.S. Jaafar, Farzad Hejazi, and Farah N.A. Abdul Aziz. "Strut-and-Tie Model for Externally Bonded CFRP-Strengthened Reinforced Concrete Deep Beams Based on Particle Swarm Optimization Algorithm: CFRP Debonding and Rupture.” Construction and Building Materials 147 (August 2017): 428-447. doi:10.1016/j.conbuildmat.2017.04.094.

[16] Mir, Mahdi, Majid Kamyab, Milad Janghorban Lariche, Amin Bemani, and Alireza Baghban. "Applying ANFIS-PSO Algorithm as a Novel Accurate Approach for Prediction of Gas Density.” Petroleum Science and Technology 36, no. 12 (March 22, 2018): 820-826. doi:10.1080/10916466.2018.1446176.

[17] Venkataiah, V., Ramakanta Mohanty, J. S. Pahariya, and M Nagaratna. “Application of Ant Colony Optimization Techniques to Predict Software Cost Estimation." Computer Communication, Networking and Internet Security (2017): 315-325. doi:10.1007/978-981-10-3226-4_32.

[18] Eberhart, Russell C., Yuhui Shi, and James Kennedy. Swarm intelligence. Elsevier, (2001).

[19] Shi, Yuhui, and Russell Eberhart. "A modified particle swarm optimizer." In 1998 IEEE international conference on evolutionary computation proceedings. IEEE world congress on computational intelligence (Cat. No. 98TH8360), IEEE, (1998): 69-73. doi:10.1109/ICEC.1998.699146.

[20] Al-Sulttani, Ali O., Amimul Ahsan, Ammar N. Hanoon, A. Rahman, N.N.N. Daud, and S. Idrus. "Hourly Yield Prediction of a Double-Slope Solar Still Hybrid with Rubber Scrapers in Low-Latitude Areas Based on the Particle Swarm Optimization Technique.” Applied Energy 203 (October 2017): 280-303. doi:10.1016/j.apenergy.2017.06.011.

[21] Salimi, Shide, Mohammed Mawlana, and Amin Hammad. "Performance Analysis of Simulation-Based Optimization of Construction Projects Using High Performance Computing." Automation in Construction 87 (March 2018): 158-172. doi:10.1016/j.autcon.2017.12.003.

[22] Banyhussan, Qais S., Ammar N. Hanoon, Ali Al-Dahawi, Gürkan Y1ldırım, and Ali A. Abdulhameed. "Development of Gravitational Search Algorithm Model for Predicting Packing Density of Cementitious Pastes.” Journal of Building Engineering 27 (January 2020): 100946. doi:10.1016/j.jobe.2019.100946.

[23] Lavanya, Dama, and Siba K. Udgata. "Swarm Intelligence Based Localization in Wireless Sensor Networks.” Multi-Disciplinary Trends in Artificial Intelligence (2011): 317-328. doi:10.1007/978-3-642-25725-4_28.

[24] Frank, Ildiko E., and Roberto Todeschini. The data analysis handbook. Vol. 14. Elsevier, (1994).

[25] Bland, J. Martin, and Douglas G. Altman. “Agreement Between Methods of Measurement with Multiple Observations Per Individual.” Journal of Biopharmaceutical Statistics 17, no. 4 (July 2, 2007): 571-582. doi:10.1080/10543400701329422.

[26] Smith, Geoffrey Nesbitt. "Probability and statistics in civil engineering." Collins professional and technical books 244 (1986).

[27] Pimentel-Gomes, F. "Course of experimental statistics." Piracicaba: FEALQ 15 (2000).

[28] Golbraikh, Alexander, and Alexander Tropsha. "Beware of Q2!” Journal of Molecular Graphics and Modelling 20, no. 4 (January 2002): 269-276. doi:10.1016/s1093-3263(01)00123-1.

[29] Roy, Partha Pratim, and Kunal Roy. "On Some Aspects of Variable Selection for Partial Least Squares Regression Models." QSAR \& Combinatorial Science 27, no. 3 (March 2008): 302-313. doi:10.1002/qsar.200710043. 